\title{
Assessment of Artificial Insemination in Camel
}

\author{
Belayneh Engidawork Demissie \\ Haramaya University, Haramaya, Ethiopia \\ Email: asir97@gmail.com
}

How to cite this paper: Demissie, B.E. (2019) Assessment of Artificial Insemination in Camel. Open Journal of Animal Sciences, 9, 207-216.

https://doi.org/10.4236/ojas.2019.92018

Received: September 17, 2018

Accepted: April 12, 2019

Published: April 15, 2019

Copyright $\odot 2019$ by author(s) and Scientific Research Publishing Inc. This work is licensed under the Creative Commons Attribution International License (CC BY 4.0).

http://creativecommons.org/licenses/by/4.0/

\begin{abstract}
The objective of this review is to confer semen collection and processing, and semen deposition technique in camel. Artificial insemination is an important technique to ensure rapid genetic improvement in camels. The use of AI has been reported in camel, although insemination trials are rare. The widely accepted methods of semen collection include electro ejaculation and artificial vagina $(\mathrm{AV})$, but flushing of the epididymis with saline solution can also be used as an alternative. Depending on the method of semen processing, semen is usually used in raw condition or after extension. Whole semen is used within minutes or after few hours in the fresh raw method. In short-term preservation or liquid semen (within a few hours or days) and long-term preservation or frozen semen (months or years), extension of the semen ejaculate is carried out by adding extenders which is required in more efficient use of AI. Semen is extended under different temperatures $\left(30^{\circ} \mathrm{C}, 25^{\circ} \mathrm{C}\right.$ or $\left.4^{\circ} \mathrm{C}\right)$, in short-term preservation. Cryopreservation is used to carry out long-term preservation. Different freezing procedures are represented by packaging methods such as ampoules or in plastic straws with different volumes $(0.25,0.5$ or $4 \mathrm{ml}$ ) and pellets. The best time for insemination can only be determined by rectal palpation of the ovaries and/or ultrasonography. The other alternative is to inseminate at known intervals following induction of ovulation by hormonal treatment with human-chorionic gonadotropin (hCG) or gonadotropin-releasing hormone (Gn-RH). The semen should be deposited into the uterus at least 24 hours after the onset of ovulation. Pregnancy rates depend on the semen extender, site of deposition and number of sperm deposited. Blood or milk progesterone assays, rectal palpation, and ultrasonic image detection of pregnancy are commonly used approaches of pregnancy diagnosis in camel.
\end{abstract}

\section{Keywords}

Insemination, Camel, Semen, Deposition, Preservation

\section{Introduction}

Artificial insemination (AI) offers many advantages to commercial animal pro- 
duction and is used routinely these days in several domestic animals such as the cow, sheep and horse [1]. The method offers the opportunity to increase the overall productivity of a particular male, thereby increasing the overall rate of genetic progress. The use of $\mathrm{AI}$ as a breeding technique has been reported in camels since the 1960s with the first camel offspring from AI being reported in a Bactrian camel in 1961 [2]. Dromedary camels are induced ovulators. Therefore, the synchronization protocols used for other domestic species are not effective in this species. This aspect could limit the application of AI, particularly if the latter has to be performed in large camel herds bred in semi intensive system. Recently, a new synchronization protocol has been proposed by [3] and later implemented by [4]. The method consists in performing a double injection of GnRH 14 days apart. In general, a single ovarian examination in a group of camels reveals the following animal categories: $10 \%$ of animals are found with the largest follicle being $<10 \mathrm{~mm}, 65 \%$ of the animals with largest follicle between $10-19$ $\mathrm{mm}$ and $25 \%$ with the largest follicle measuring more than $20 \mathrm{~mm}$ [4]. The percentage of females with the largest follicle of $10-19 \mathrm{~mm}$ would increase to $90 \%$, 14 days after the 2nd injection of GnRH [4]. This method would be a very useful tool for synchronizing ovarian follicular wave and performing fixed time mating or AI on a large group of animals but providing that a sufficient number of bulls or semen doses (either fresh, cooled or frozen) are available for the timed mating or the inseminations. For performing the AI, the semen should be deposited, through bovine or equine insemination catheters, just cranial to the cervix, into the uterus. Indeed, during mating, the semen is deposited partly into the uterus and partly intracervically, due to the particular twisting movement of the glans penis [5]. The cervix could be located by transvaginal approach (as AI performed in the mare) or by transrectal guiding of the insemination catheter. It is verified that a lower dose of sperm could be equally effective for obtaining pregnancies if the sperms are released near the Utero-Tubarian Junction, left or right, according to the position of the preovulatory follicle [6]. Since effective estrus detection requires time, skills and expenses, these have often been major constrains limiting the wide spread of AI. In addition, the nature of camel herds spreads widely in the desert which makes estrus monitoring very hard to be applied. Therefore, the current review was carried out to discuss semen collection, processing and preservation, manipulation of the female and semen deposition in camel.

\section{Semen Collection}

Semen collection in camels presents many difficulties partly because they mate in sternal recumbancy, have a lengthy ejaculation throughout copulation, which lasts from 5 - 20 minutes, and the semen is highly viscous [1]. Semen can be collected using a modified bull artificial vagina $(30 \mathrm{~cm}$ long, $5 \mathrm{~cm}$ internal diameter) with a foam imitation cervix, of about $8 \mathrm{~cm}$ in length, placed inside the AV [7]. The artificial vagina (AV) is prepared by filling with water at $55^{\circ} \mathrm{C}-60^{\circ} \mathrm{C}$ to 
give an internal temperature of $38^{\circ} \mathrm{C}-40^{\circ} \mathrm{C}$, and air is pumped between the inner liner and outer rigid wall to create pressure inside the AV to stimulate ejaculation. A clear, glass water-jacketed $\left(35^{\circ} \mathrm{C}-37^{\circ} \mathrm{C}\right)$ semen vessel is attached to the apex of the internal latex rubber liner to keep the semen warm during the lengthy ejaculation process and the entrance of the AV is lubricated with KY jelly before use. To collect the semen a sexually receptive female is used for the bull to mount but before he enters the female he is guided into the AV. The semen is usually ejaculated in fractions and this whole process can take between 5 and 10 minutes, although it may occasionally last for 20 minutes or longer [8]. As the collection procedure can be rather prolonged it can be advantageous to add about $1-2 \mathrm{ml}$ of extender to the collection vessel before the collection.

\subsection{Semen Evaluation}

Once collected, the semen has to be evaluated and the following parameters should be noted: volume (usually between 2 - $10 \mathrm{ml}$ ), color (creamy white), concentration (usual range between $200-300 \times 10^{6} / \mathrm{ml}$ ) [9], and motility. One of the main problems with camel semen is its high viscosity which makes handling and estimation of the spermatozoa parameters difficult. This viscosity is usually attributed to the presence of mucopolysaccharides from secretions of the bulbourethral gland or the prostate, but the degree of viscosity depends on the individual male and on the quantity of the gel fraction in the ejaculate. According to some authors the semen will partially liquefy if stored at $25^{\circ} \mathrm{C}-37^{\circ} \mathrm{C}$ for $10-20$ minutes [10] [11] but other studies show it can take up to 8 hours [5]. Enzymatic methods using trypsin, collagenase and chymotrypsin as well as mechanical methods using centrifugation, density gradient centrifugation, vortexing and gentle pipetting have been investigated to try and reduce viscosity, and gentle pipetting was the most successful as it did least damage to the spermatozoa [1].

\subsection{Short Term Semen Preservation}

Semen preservation and insemination of dromedary camel have been studies by several authors [7] [9] [12], but majority the studies reported low post-thaw motilities and few, if any, pregnancies with AI of chilled or frozen semen [13]. This could be because of the difficulties involved in collecting semen from male camels and that the ejaculates are of low volume, low sperm concentration and are highly viscous. Several extenders have been used for dilution of freshly collected camel semen [14] such as skimmed milk-glucose extender [15], Dimitropolous 11, [16], Laiciphos [17], Androhep [18], glucose-EDTA [19], sodium-citrate-egg yolk [20], lactose-egg yolk [9], and Green buffer-egg yolk [3]. Most of these extenders contain an energy source (glucose or fructose), a protein for cold shock protection (lipoprotein from egg yolk or casein from milk), a buffering system and antibiotics. Once collected the semen is diluted with warmed $\left(30^{\circ} \mathrm{C}-35^{\circ} \mathrm{C}\right)$ extender added slowly to the semen in a ratio of 1:1 - 3:1 (extender: semen) depending on the concentration of the ejaculate. It is better to let the semen liquefy 
before insemination to aid better mixing of the semen with the extender and to allow more accurate assessments of concentration and motility.

Sperm motility was better in Laiciphos (60\%) and Androhep (68\%) compared with Glucose-EDTA (42\%) nevertheless no pregnancy results were reported [14], however pregnancy rates of 50\% was achieved with an extender containing $11 \%$ lactose and $20 \%$ egg yolk [9]. In a subsequent study the best pregnancy rates were achieved with Laciphos $+20 \%$ egg yolk (53\%), although two subsequently aborted, and Green Buffer $+20 \%$ egg yolk (47\%) compared with other extenders such as skimmed milk extender [3]. More recently, further studies have compared the extender INRA-96 (I.M.V.) with Green Buffer. Results showed that motility was higher after dilution in Green Buffer (67\%) compared with INRA-96 (59\%) whereas, pregnancy rates were unaffected by diluent, Green Buffer (34\%) and INRA-96 (34\%) [21].

\subsection{Induced Ovulation and Corpus Luteum Development}

The follicle is responsive to ovulate during its dominant phase; in natural mating, the intravenous injection of $20 \mathrm{mg}$ of Buserelin, or of $3000 \mathrm{IU}$ of human chorionic gonadotropin (hCG) are equally efficacious in inducing ovulation but the crucial factor for ensuring the occurrence of ovulation is the diameter of the dominant [22]. Ovulation rates of $85 \%$ are achieved if it measures between 10 and $19 \mathrm{~mm}$ in diameter, but ovulation rates dramatically drop to $12.5 \%$ if the follicle measures between $20-29 \mathrm{~mm}$. Follicles with diameter $>30 \mathrm{~mm}$ cannot ovulate as well as follicles during the regression phase [22].

Although follicles of only $10 \mathrm{~mm}$ in diameter acquire the ability to ovulate, the functionality of the developed Corpus luteum (CL) is impaired; consequently it is not advisable to induce ovulation in follicles less than $12 \mathrm{~mm}$ [4] [22]. It is suggested to induce ovulation and to perform timed mating or artificial insemination when the dominant follicle measures between 13 and $18 \mathrm{~mm}$ [12]. Ovulation occurs 24 - 36 hours after the stimuli [23]; 31 hours in average, according to [24]. The Corpus Luteum (CL) starts developing 3 - 4 days after the inducing stimulus and reaches its maximum size by days 8 - 9 [23]. In absence of pregnancy the corpus luteum starts regressing 9 - 10 days post-mating [22] [25]. Progesterone concentrations remain low for 3 days then increase to maximum values by day 8 - 9 and decrease to basal concentrations by day $11-12$ [22] [23].

The short luteal lifespan entails that the camel conceptus must send an antiluteolytic signal to the endometrium by day 7 or 8 to maintain CL [3]. In case of maternal recognition of pregnancy the CL continues to grow until day 35 [26]. A marked increase of PGF2 $\alpha$ have been observed 8 - 10 days post mating in female camels when the maternal recognition of pregnancy did not occur; the PGF2 $\alpha$ increase corresponds with the progesterone decline, indicating that luteolysis is mediated by the PGF $2 \alpha$ action. Both PGF $2 \alpha$ and progesterone concentrations return to basal levels by day 12 after mating. The PGF $2 \alpha$ involvement in the luteolysis of dromedary camel was demonstrated by the suppressive effect of mec- 
lofenamic acid (a prostaglandin synthetase inhibitor), the latter could be used to prevents luteolysis and synchronize recipients for Embryo transfer procedures [27].

\section{Follicular Wave Pattern}

Camels are "induced ovulators" and normally ovulate only in response to mating; follicles tend to grow, have a period of maturity during which are capable to ovulate, and then regress if ovulation is not induced [28]. The changes in the ovarian follicular dynamics in dromedary camels are described as a "follicular wave pattern". Each follicular wave is divided into four phases namely: "recruitment phase", "growth phase", "mature phase" and "regression phase" [5] [22] [25]. The Recruitment phase corresponds to the start of a new follicular wave; about 12 follicles (range 8 - 34) could be recruited in this phase [29]. The follicular growth follows the recruitment phase; 3 - 6 follicles grow until they reach approximately $8 \mathrm{~mm}$ in diameter (duration: $6.10 \pm 0.15$ days). The Mature Phase (or dominance) starts when one or two growing follicles become dominant (duration: $10.20 \pm 0.47$ days) and ends when the dominant follicle (DF) lose its dominance and allows the emergence of the next follicular wave; the diameter of the dominant follicle could continue increasing during this phase [29].

The uterine tone and edema steadily increase from follicular growth to the dominance phase. The organ become turgid particularly during the follicular dominance and then the tone is slowly lost once the follicle starts its regression phase [25]. The follicular Regression Phase occurs after the mature phase and is due to the absence of mating or ovulation inducing treatment; it last, in average, $11.9 \pm 0.8$ days if the mature follicle measures $15-25 \mathrm{~mm}$. During the regression phase the echotexture and tone of the uterus depend on the development reached by the new follicular wave [22] [25] [29]. In some cases about $50 \%$ of dominant follicles continue to grow, even after losing their dominance, reaching a mean maximum diameter of $42 \mathrm{~mm}$ (range $40-64 \mathrm{~mm}$ ), before start regressing. These large oversize follicles, however, do not inhibit the growth and responsiveness to ovulatory stimulus of other follicles, in the same or contralateral ovary. Overlarge follicles sometimes become luteinized and produce levels of progesterone similar to that observed in presence of a Corpus Luteum [3] [25].

\subsection{Use of Extended Semen}

Pregnancy rates of 50\% have been achieved after diluting semen with an extender containing $11 \%$ lactose and $20 \%$ egg yolk [28]. Similar pregnancy rates were achieved with Laciphos and 20\% egg yolk (53\% pregnancy rate), and Green Buffer and $20 \%$ egg yolk (47\% pregnancy rate). Recent studies have proved that it is possible to obtain $72 \%$ pregnancy rates by using $1.5-3.5 \mathrm{ml}$ of semen $\left(150 \times 10^{6}\right.$ spermatozoa/ml) extended with green buffer and $20 \%$ egg yolk but providing that the Green Buffer extender have not been previously frozen, as the freezing process is deleterious for the preservation properties of this extender [30]. Preg- 
nancy rates could be possibly improved through the use of a higher concentration of sperms $\left(300 \times 10^{6}\right.$ spermatozoa/ml). The semen (either fresh or chilled) should be deposited into the uterus at least 24 hours after induction of ovulation [13].

\subsection{Use of Chilled and Frozen Semen}

Pregnancy rates (PR) of $17.6 \%$ have been obtained by depositing $150 \times 10^{6}$ motile sperms chilled in the INRA 96 extender. No pregnancies were obtained by using same sperm concentration but diluted with Green Buffer extender. Such results have been improved to $10.5 \%$ by using $300 \times 10^{6}$ motile sperms and to $25 \%$ with $600 \times 10^{6}[21]$. Results of semen freezing protocol and pregnancy rates by using frozen semen are not satisfactory in the dromedary camel species. Green/Clear buffers, 20\% egg yolk and 6\% glycerol is the best combination for freezing dromedary camel semen, but although $50 \%$ of spermatozoa were motile after cooling, this percentage was reduced to $35 \%$ immediately post-thaw, and to $0 \% 3$ hour post thaws [28]. However, tris-lactose containing a final concentration of $3 \%$ glycerol recorded the highest post-thaw motility (45.8\%) with the highest survival rate $(73.3 \%)$ but did not report pregnancy rates using such freezing-thawing protocol [31].

\subsection{Optimum Number of Spermatozoa to Inseminate and Site of Insemination}

Fibroscopic evaluation of the camel's cervix before and after mating has shown that semen is deposited partly intra-uterine and partly intra-cervical [5]. Therefore in AI, semen is generally inseminated directly into the uterus using a bovine insemination catheter passed through the camel's cervix. Pregnancy rates of 50\% have been achieved after insemination of $300 \times 10^{6}$ live spermatozoa [7] or as few as $100 \times 10^{6}$ [9] directly into the uterine body. However, when it is deposited just into the body of the uterus there can be a considerable loss of spermatozoa, due to backflow of semen through the relatively short cervix. A further study was therefore carried out to investigate whether better results could be achieved if the semen was deposited at the tip of the horn, rather than the body of the uterus [12]. The advantage of deep uterine insemination is that the semen is deposited nearer the uterine junction and therefore should reduce the number of spermatozoa needed for successful fertilization [32].

In the study by [12] a total of 40,80 or $150 \times 10^{6}$ motile spermatozoa were deposited either just through the cervix into the uterine body or at the tip of the uterine horn ipsilateral with the ovary containing the dominant follicle. The results indicate that although a pregnancy rate of $53 \%$ or $43 \%$ could be achieved after insemination of $150 \times 10^{6}$ motile spermatozoa into the body of the uterus or at the tip of the horn respectively, a pregnancy rate of $40 \%$ could also be achieved when a reduced number of only $80 \times 10^{6}$ spermatozoa were deposited at the tip of the uterine horn [12]. However, as only one camel inseminated with $40 \times 10^{6}$ spermatozoa at the tip of the horn conceived it would suggest that per- 
haps $80 \times 10^{6}$ is the minimum number of sperm needed to establish a pregnancy by deep intrauterine insemination [12].

\section{Pregnancy Diagnosis}

Blood or milk progesterone assays can be a valuable tool for diagnosis of pregnancy in camel. Clinical diagnosis of pregnancy in camel by rectal palpation for each month of gestation has been recommended technique for pregnancy diagnosis in the field [26] [33]. Ultrasonic image detection of pregnancy [34] can also be used. Positive pregnancy diagnosis can be achieved only if the CL and fetus are palpated [3]. Uterine changes due to pregnancy can be detected by rectal palpation 45 day after mating, and the first sign is an increase in the diameter of the left horn. Besides, a close relationship between corpus luteum function and the behavioral response of the females in the presence of males has been found to be an excellent means of pregnancy diagnosis [35].

\section{Conclusion}

The use of AI technique in camel can be employed to impregnate as much females as possible at the start of the breeding season, which permits to be impregnated again, after parturition. In addition, successful freezing of semen and its transport to different countries would lead to the genetic improvement of camel stock worldwide. Artificial insemination and induction of ovulation may be a promising process. However, the efficiency of the cryopreserved semen doses (post-motility) and site of insemination with good understanding of ovulation mechanisms either during natural mating or through hormonal treatments, specially the detection of the mechanical-hormonal relationship on ovulation should be taken in to consideration. Further studies should be conducted to address various problems involved and to improve cryopreservation of camel semen, so that pregnancy rates can be increased with frozen semen.

\section{Acknowledgements}

The author is grateful for any support received from Haramaya University and staff of the School of Animal And Range Sciences for their assistances in preparing the review.

\section{Conflicts of Interest}

The authors declare no conflicts of interest regarding the publication of this paper.

\section{References}

[1] Adams, G.P., Ratto, M.H., Collins, C.W. and Bergfelt, D.R. (2009) Artificial Insemination in South American Camelids and Wild Equids. Theriogenology, 71, 166-175. https://doi.org/10.1016/j.theriogenology.2008.09.005

[2] Elliot, F.I. (1961) Artificial Insemination of Bactrian Camel (Camelus bactrianus). 
International Zoo Yearbook, 3, 94.

[3] Skidmore, J.A., Billah, M. and Allen, W.R. (2000) Using Modern Reproductive Technologies Such as Embryo Transfer and Artificial Insemination to Improve the Reproductive Potential of Dromedary Camels. Revue délevage et de médecine vétérinaire des pays tropicaux, 53, 97-100.

[4] Nagy, P. and Juhasz, J. (2008) Effect of Different GnRH Analogue and Follicular Size on Ovulation and CL Development in Dromedary Camels (Camelus dromedarius). Proceedings of 16 th International Congress on Animal Reproduction, Budapest, 13-17 July 2008, 95.

[5] Tibary, A. and Anouassi, A. (1997) Theriogenology in Camelidae. Anatomy, Physiology and Pathology and Artificial Breeding. Veterinary Research Centre, Ministry of Culture and Information, Abu Dhabi.

[6] Skidmore, J.A. and Billah, M. (2006) Investigation of the Most Appropriate Time for Insemination of Female Camels (Camelus dromedarius) after GnRH Injection and Comparison of Pregnancy Rates after Deep Intra-Uterine versus Cervical Insemination. Proceedings of First Conference of International Society of Camelids Research and Development, Al Ain, 15-17 April 2006, 54.

[7] Bravo, P.W., Skidmore, J.A. and Zhao, X.X. (2000) Reproductive Aspects and Storage of Semen in Camelidae. Animal Reproduction Science, 62, 173-193.

[8] Rai, A.K., Tandon, S.N. and Khanna, N.D. (1988) Copulation Time of Bikaneri Male Camels. Indian Journal of Animal Sciences, 58, 1202-1203.

[9] Anouassi, A., Adnani, M. and El-Raed (1992) Artificial Insemination in the Camel Requires Induction of Ovulation to Achieve Pregnancy. Proceedings of the First International Camel Conference, Dubai, 175-177.

[10] Abdel Rahim, S.E.A. and El Nazier, A.E. (1990) Factors Affecting Camel Reproductive Performance in the Tropics. Proceeding of the Workshop: Saint Martin, Paris, 10-12 September 1990, 73.

[11] Muss, B., Siam, H., Mert, H., et al. (1993) Manipulation of Reproductive Function in Male and Female Camels. Animal Reproduction Science, 33, 289-306.

[12] Skidmore, J.A. and Billah, M. (2006) Comparison of Pregnancy Rates in Dromedary Camels (Camelus dromedarius) after Deep Intra-Uterine versus Cervical Insemination. Theriogenology, 66, 292-296.

[13] Deen, A., Vyas, S. and Sahani, M.S. (2003) Semen Collection, Cryopreservation and Artificial Insemination in the Dromedary Camel. Animal Reproduction Science, 77, 223-233.

[14] Sieme, H., Merkt, H., Musa, B., Hego, B.E.O. and Willem, T. (1990) Liquid and Deep Freeze Preservation of Camel Semen Using Different Extenders and Methods. Proceedings of Workshop: Is It Possible to Improve the Reproductive Performance of the Camel, Paris, 273-284.

[15] Kenney, R.M., Bergmann, R.V., Cooper, W.L. and Morse, G.W. (1975) Minimal Contamination Techniques for Breeding Mares: Technique and Preliminary Findings. Proceeding of the Annual Conference of American Society of Equine Practitioners, 21, 327-336.

[16] Rasbech, N.O. (1984) Instrumental Inseminiesing Hesteavlen. Dansk Veterinaria, Tidsskr, 67, 11-16.

[17] Cassou, M.R. (1959) Derzitiger stand der vertahrem zur konserviesung vou bullensperme. Deutsche tierärztliche Wochenschrift, 68, 115-119.

[18] Waberski, D., Weitze, K.F., Rath, D. and Sullmann, H.P. (1989) Wirking von bovine 
srumalbumin and zwitterionenpuffer and fluessigkonserviertn ebersamen. Zuchthygiene, 24, 126-133.

[19] Pan, G.W., Zhao, X.X., Chen, B.X., Jiang, S., Huang, Y.M., Zu, Y.S. and Wang, H.Y. (1992) The Ovulation-Inducing Effect of Seminal Plasma in the Bactrian Camel. In: Allen, W.R., Higgins, A.J., Mayhew, I.G., Snow, D.H. and Wade, J.F., Eds., Proceedings of the 1 st International Camel Conference, R\&W Publications, Newmarket, 159-162.

[20] Kupper, H. (1954) Versuche zur Verduennung des Hengstspermas. Thesis, Tieraerztl. Hochschule, Hannover.

[21] Morton, K.M., Billah, M. and Skidmore, J.A. (2010) Artificial Insemination of Dromedary Camels with Fresh and Chilled Semen: Effect of Diluent and Sperm Dose, Preliminary Results. In: Proceedings of the Eighth International Symposium on Reproduction in Domestic Ruminants, Nottingham University Press, 493.

[22] Skidmore, J.A., Billah, M. and Allen, W.R. (1996) The Ovarian Follicular Wave Pattern and Induction of Ovulation in the Mated and Non-Mated One Humped Camel. Journal of Reproduction and Fertility, 106, 185-192.

[23] Marie, M. and Anouassi, A. (1987) Induction of Luteal Activity and Progesterone Secretion in the Non-Pregnant One-Humped Camel (Camelus dromedarius). Journal of Reproduction \& Infertility, 80, 183-192. https://doi.org/10.1530/jrf.0.0800183

[24] Manjunatha, B.M., Pratap, N. and Hago, B.E. (2011) Acquisition of Ovulatory Capacity in Camel (Camelus dromedarius) Follicles.

http://www.camelidconference.com/resources/dyn

[25] Tibary, A. and Anouassi, A. (1996) Ultrasonographic Changes of the Reproductive Tract in the Female Camel (Camelus dromedarius) during the Follicular Cycle and Pregnancy. Journal of Camel Practice and Research, 3, 71-90.

[26] Musa, B.E. and Abusineina, M.E. (1978) Clinical Pregnancy in the Camel and a Comparison with Bovine Pregnancy. Veterinary Record, 102, 7-10.

[27] Skidmore, J.A., Starbuck, G.R., Lamming, G.E. and Allen, W.R. (1998) Control of Luteolysis in the One-Humped Camel (Camelus dromedarius). Journal of Reproduction and Fertility, 114, 201-209.

[28] Skidmore, J.A., Morton, K.M. and Billah, M. (2013) Artificial Insemination in Dromedary Camels. Animal Reproduction Science, 136, 178-186. https://doi.org/10.1016/j.anireprosci.2012.10.008

[29] Manjunatha, B.M., Pratap, N., Al-Bulushi, S. and Hago, B.E. (2012) Characterization of Ovarian Follicular Dynamics in Dromedary Camels (Camelus dromedarius). Theriogenology, 78, 965-973. https://doi.org/10.1016/j.theriogenology.2012.05.011

[30] Morton, K.M., Billah, M. and Skidmore, J.A. (2011) Effect of Green Buffer Storage on the Fertility of Fresh Camel Semen after Artificial Insemination. Reproduction in Domestic Animals, 46, 554-557. https://doi.org/10.1111/j.1439-0531.2010.01678.x

[31] El-Bahrawy, K.A. (2010) Cryopreservation of Dromedary Camel Semen Supplemented with $\alpha$-Amylase Enzyme. Journal of Camel Practice and Research, 17, 211-216.

[32] Lopez-Gatius, F. (2000) Site of Semen Deposition in Cattle: A Review. Theriogenology, 53, 1407-1414.

[33] Arthur, G.H., Al-Rahim, A.T. and Al-Hindi, A.S. (1985) The Camel in Health and Disease. VII. Reproduction and Genital Disease of the Camel. British Veterinary Journal, 141, 650-659.

[34] Schlels, H.F. and Mostafawi, D.J. (1978) Ultrasonic Pregnancy Diagnosis in the Ca- 
mel. Animal Reproduction Science, 1, 19-23.

[35] Fernandez-Baca, S. (1993) Manipulation of Reproductive Functions in Male and Female New World Camelids. Animal Reproduction Science, 33, 307-323. 